Document downloaded from:

http://hdl.handle.net/10251/44311

This paper must be cited as:

Esteve Bosch, R.; Marí Romero, AF.; Mora Mas, FJ.; Pérez Aparicio, JL.; Toledo Alarcón, JF.; Alvarez, V.; Bandac, I.... (2013). Radiopurity control in the NEXT-100 double beta decay experiment: procedures and initial measurements. Journal of Instrumentation. 8(1):1-19. doi:10.1088/1748-0221/8/01/T01002.

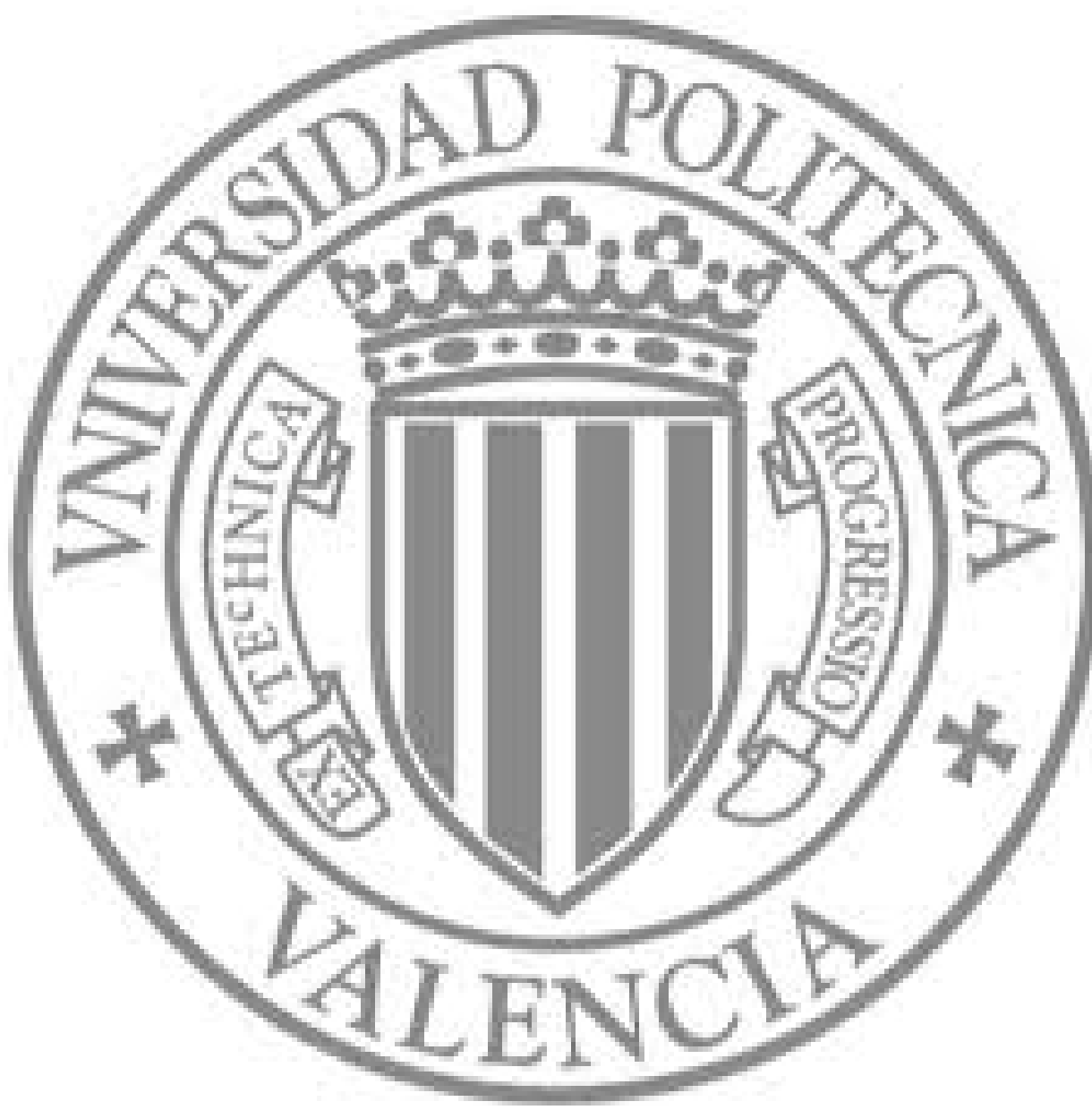

The final publication is available at

http://dx.doi.org/10.1088/1748-0221/8/01/T01002

Copyright

IOP Publishing: Hybrid Open Access 


\title{
Radiopurity control in the NEXT-100 double beta decay experiment: procedures and initial measurements
}

\author{
V. Álvarez, ${ }^{a}$ I. Bandac, ${ }^{b}$ A. Bettini, ${ }^{b, c}$ F.I.G.M. Borges, ${ }^{d}$ S. Cárcel, ${ }^{a}$ J. Castel,,${ }^{b, e}$ \\ S. Cebrián, ${ }^{b, e *}$ A. Cervera, ${ }^{a}$ C.A.N. Conde, ${ }^{d}$ T. Dafni, ${ }^{b, e}$ T.H.V.T. Dias, ${ }^{d}$ J. Díaz, ${ }^{a}$ \\ M. Egorov, ${ }^{f}$ R. Esteve, ${ }^{g}$ P. Evtoukhovitch, ${ }^{h}$ L.M.P. Fernandes,${ }^{d}$ P. Ferrario, ${ }^{a}$ \\ A.L. Ferreira, ${ }^{i}$ E.D.C. Freitas, ${ }^{d}$ V.M. Gehman, ${ }^{f}$ A. Gil, ${ }^{a}$ A. Goldschmidt, ${ }^{f}$ \\ H. Gómez, ${ }^{b, e \dagger}$ J.J. Gómez-Cadenas, ${ }^{a \ddagger}$ D. González-Díaz, ${ }^{b, e}$ R.M. Gutiérrez, ${ }^{j}$ \\ J. Hauptman, ${ }^{k}$ J.A. Hernando Morata, ${ }^{l}$ D.C. Herrera, ${ }^{b, e}$ F.J. Iguaz, ${ }^{b, e}$ I.G. Irastorza, ${ }^{b, e}$ \\ M.A. Jinete, ${ }^{j}$ L. Labarga, ${ }^{m}$ A. Laing, ${ }^{a}$ I. Liubarsky, ${ }^{a}$ J.A.M. Lopes, ${ }^{d}$ D. Lorca, ${ }^{a}$ \\ M. Losada, ${ }^{j}$ G. Luzón, ${ }^{b, e}$ A. Marí, ${ }^{g}$ J. Martín-Albo, ${ }^{a}$ A. Martínez, ${ }^{a}$ T. Miller, ${ }^{f}$ \\ A. Moiseenko, ${ }^{h}$ F. Monrabal, ${ }^{a}$ C.M.B. Monteiro, ${ }^{d}$ F.J. Mora, ${ }^{g}$ L.M. Moutinho, ${ }^{i}$ \\ J. Muñoz Vidal, ${ }^{a}$ H. Natal da Luz, ${ }^{d}$ G. Navarro,,${ }^{j}$ M. Nebot-Guinot, ${ }^{a}$ D. Nygren, ${ }^{f}$ \\ C.A.B. Oliveira, ${ }^{f}$ A. Ortiz de Solórzano, ${ }^{b, e}$ R. Palma, ${ }^{n}$ J. Pérez, ${ }^{o}$ J.L. Pérez Aparicio, ${ }^{n}$ \\ J. Renner, ${ }^{f}$ L. Ripoll, ${ }^{p}$ A. Rodríguez, ${ }^{b, e}$ J. Rodríguez, ${ }^{a}$ F.P. Santos, ${ }^{d}$ J.M.F. dos \\ Santos, ${ }^{d}$ L. Segui,,${ }^{b, e}$ L. Serra, ${ }^{a}$ D. Shuman, ${ }^{f}$ A. Simón,,${ }^{a}$ C. Sofka,,${ }^{q}$ M. Sorel, ${ }^{a}$ \\ J.F. Toledo, ${ }^{g}$ A. Tomás, ${ }^{b, e}$ J. Torrent, ${ }^{p}$ Z. Tsamalaidze, ${ }^{h}$ D. Vázquez, ${ }^{l}$ J.F.C.A. Veloso, ${ }^{i}$ \\ J.A. Villar, ${ }^{b, e}$ R.C. Webb, ${ }^{q}$ J.T. White ${ }^{q}$ and N. Yahlali ${ }^{a}$
}


a Instituto de Física Corpuscular (IFIC), CSIC \& Universitat de València

Calle Catedrático José Beltrán, 2, 46980 Paterna, Valencia, Spain

${ }^{b}$ Laboratorio Subterráneo de Canfranc

Paseo de los Ayerbe s/n, 22880 Canfranc Estación, Huesca, Spain

c Padua University and INFN Section, Dipartimento di Fisca G. Galilei, Via Marzolo 8, 35131

Padova, Italy

${ }^{d}$ Departamento de Fisica, Universidade de Coimbra

Rua Larga, 3004-516 Coimbra, Portugal

e Laboratorio de Física Nuclear y Astropartículas, Universidad de Zaragoza

Calle Pedro Cerbuna 12, 50009 Zaragoza, Spain

${ }^{f}$ Lawrence Berkeley National Laboratory (LBNL)

1 Cyclotron Road, Berkeley, California 94720, USA

${ }^{g}$ Instituto de Instrumentación para Imagen Molecular (I3M), Universitat Politècnica de València

Camino de Vera, s/n, Edificio 8B, 46022 Valencia, Spain

${ }^{h}$ Joint Institute for Nuclear Research (JINR)

Joliot-Curie 6, 141980 Dubna, Russia

institute of Nanostructures, Nanomodelling and Nanofabrication (i3N), Universidade de Aveiro

Campus de Santiago, 3810-193 Aveiro, Portugal

j Centro de Investigaciones en Ciencias Básicas y Aplicadas, Universidad Antonio Nariño

Carretera 3 este No. 47A-15, Bogotá, Colombia

${ }^{k}$ Department of Physics and Astronomy, Iowa State University

12 Physics Hall, Ames, Iowa 50011-3160, USA

${ }^{l}$ Instituto Gallego de Física de Altas Energías (IGFAE), Univ. de Santiago de Compostela

Campus sur, Rúa Xosé María Suárez Núñez, s/n, 15782 Santiago de Compostela, Spain

${ }^{m}$ Departamento de Física Teórica, Universidad Autónoma de Madrid

Campus de Cantoblanco, 28049 Madrid, Spain

${ }^{n}$ Dpto. de Mecánica de Medios Continuos y Teoría de Estructuras, Univ. Politècnica de València

Camino de Vera, s/n, 46071 Valencia, Spain

o Instituto de Física Teórica (IFT), UAM/CSIC

Campus de Cantoblanco, 28049 Madrid, Spain

${ }^{p}$ Escola Politècnica Superior, Universitat de Girona

Av. Montilivi, s/n, 17071 Girona, Spain

${ }^{q}$ Department of Physics and Astronomy, Texas A\&M University

College Station, Texas 77843-4242, USA

Abstract: The "Neutrino Experiment with a Xenon Time-Projection Chamber" (NEXT) is intended to investigate the neutrinoless double beta decay of ${ }^{136} \mathrm{Xe}$, which requires a severe suppression of potential backgrounds. An extensive screening and material selection process is underway for NEXT since the control of the radiopurity levels of the materials to be used in the experimental set-up is a must for rare event searches. First measurements based on Glow Discharge Mass Spectrometry and gamma-ray spectroscopy using ultra-low background germanium detectors at the Laboratorio Subterráneo de Canfranc (Spain) are described here. Activity results for natural radioactive chains and other common radionuclides are summarized, being the values obtained for some materials like copper and stainless steel very competitive. The implications of these results for the NEXT experiment are also discussed. 
KeYwORDS: Double beta decay; Time-Projection Chamber (TPC); Gamma detectors (HPGe); Search for radioactive material.

\footnotetext{
*Corresponding author (scebrian@unizar.es).

†Present address: Laboratoire de l’Accélérateur Linéaire (LAL). Centre Scientifique d’Orsay. Bâtiment 200 - BP 34. 91898 Orsay Cedex, France.

‡Spokesperson (gomez@mail.cern.ch).
} 


\section{Contents}

1. Introduction 1

2. Techniques and equipment 3

2.1 GDMS

2.2 Germanium gamma-ray spectrometry

3. Measurements and results 8

3.1 Shielding 12

3.2 Vessel 13

3.3 High Voltage and Electroluminescence components 14

3.4 Energy and tracking planes components 15

4. Summary 16

\section{Introduction}

The observation of neutrinoless double beta decay as a peak in the sum energy of the two emitted electrons $\left(Q_{\beta \beta}\right)$, would show that neutrinos are Majorana particles and contribute to the determination of their mass hierarchy (see for instance [1]). The NEXT experiment ("Neutrino Experiment with a $\underline{X}$ enon Time-Projection Chamber") will search for such a decay in ${ }^{136} \mathrm{Xe}$ using a highpressure gaseous xenon Time-Projection Chamber (TPC) with a source mass of the order of 100 $\mathrm{kg}$ at the Laboratorio Subterráneo de Canfranc (LSC) [2], located at the Spanish Pyrenees. The NEXT-100 detector design [3] is intended to combine, keeping the detector=source approach, the measurement of the topological signature of the event (to discriminate the signal from background) with the energy resolution optimization; this is possible thanks to the use of proportional electroluminescent (EL) amplification. As illustrated in figure 1, energy and tracking readout planes are located at opposite sides of the pressure vessel using different sensors: photomultiplier tubes (PMTs) for calorimetry (and for fixing the start of the event) and silicon multi-pixel photon counters (MPPCs) for tracking. Energy resolution below $1 \%$ FWHM at the $Q_{\beta \beta}$ energy seems reachable [3]. The expected sensitivity of NEXT is very competitive; electron neutrino effective Majorana masses below $100 \mathrm{meV}$ could be explored for a total exposure of $500 \mathrm{~kg} \cdot y e a r$ [ []. The Technical Design Report of the experiment was presented in 2011, while work on prototypes is ongoing [5].

Operating in deep underground locations and using both active and passive shields is mandatory in experiments searching for rare phenomena like the nuclear double beta decay, the direct detection of dark matter and the interaction of low-energy neutrinos [6, 7]. A careful selection of radiopure materials to be used in the experimental set-up based on precise measurements of ultralow radioactivity is also compulsory in these experiments in order to achieve, for example in NEXT, 


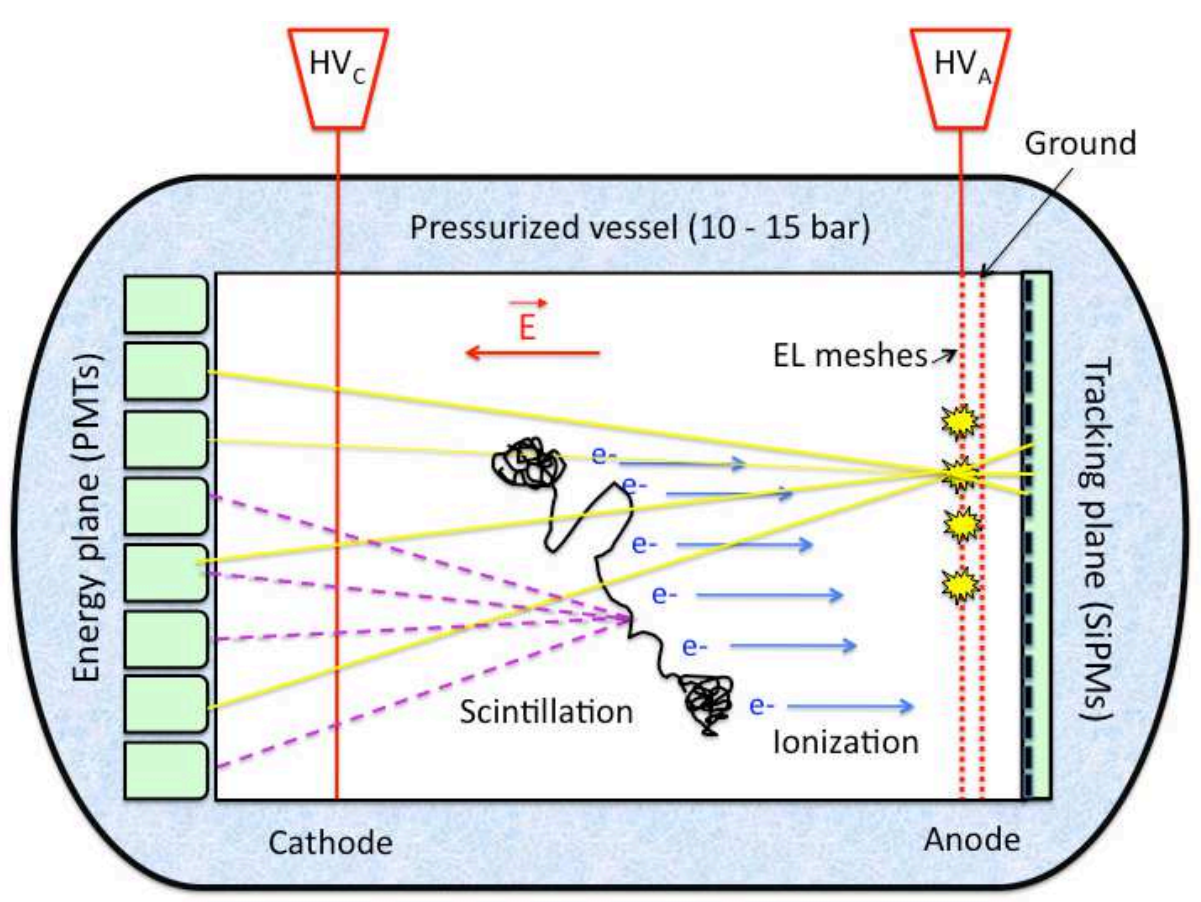

Figure 1. Concept of the NEXT experiment: light from the Xe electroluminescence (EL) generated at the anode is recorded both in the photosensor plane right behind it for tracking and in the photosensor plane behind the transparent cathode for a precise energy measurement. Primary scintillation defining the start of the event is also detected by the cathode photosensors.

a background level of $8 \times 10^{-4}$ counts $\mathrm{keV}^{-1} \mathrm{~kg}^{-1} \mathrm{y}^{-1}$ in the energy region of interest (RoI) [3] . A great effort has been done by several collaborations to measure the radiopurity of many different materials (see for instance Refs. [8]-[19]) and information has been compiled and made public [20, 21]. Although these data are extremely useful and can be used as a starting point in the selection of materials for any experiment, a thorough radiopurity control of the relevant components to be actually used must be always undertaken since radiopurity requirements are stringent.

The ability to discriminate signal from background is a powerful tool in NEXT. Signal events will appear uniformly distributed in the source volume of enriched xenon and will have a distinctive topology (a twisted long track, about $30 \mathrm{~cm}$ long at $10 \mathrm{bar}$, with blobs at both ends). Defining a fiducial volume eliminates all charged backgrounds entering the detector while confined tracks generated by neutral particles, like high-energy gammas, can be suppressed by pattern recognition. Thus, the relevance of a background source depends on its probability of generating a signallike track in the active volume with energy around $\mathrm{Q}_{\beta \beta}$. The neutrinoless double beta decay of ${ }^{136} \mathrm{Xe}$ would produce a peak at $Q_{\beta \beta}=2.458 \mathrm{MeV}$ [22]; the main background sources at the NEXT experiment are the gamma lines at $2.615 \mathrm{MeV}$ from ${ }^{208} \mathrm{Tl}$ and at $2.448 \mathrm{MeV}$ from ${ }^{214} \mathrm{Bi}$. These isotopes produced at the lower part of the natural radioactive chains of ${ }^{232} \mathrm{Th}$ and ${ }^{238} \mathrm{U}$ respectively.

- For the $2.615 \mathrm{MeV}$ line, the Compton edge is well below $\mathrm{Q}_{\beta \beta}$, but a scattered gamma can interact and produce other electron tracks close enough to the initial Compton electron, so they are reconstructed as a single object falling in the RoI. These photons can also be scattered 
outside the detector and then suffer photoelectric absorption inside contributing to the RoI. In addition, photoelectric electrons from the $2.615 \mathrm{MeV}$ emission are produced above the RoI but can lose energy via bremsstrahlung and populate the energy window, if the emitted photons escape out of the detector.

- The gamma line at $2.448 \mathrm{MeV}$ is dangerous in spite of its low intensity (1.57\%) because it is very close to $\mathrm{Q}_{\beta \beta}$.

Both ${ }^{208} \mathrm{Tl}$ and ${ }^{214} \mathrm{Bi}$ are in the progeny of $\mathrm{Rn}$ isotopes $\left({ }^{220} \mathrm{Rn}\right.$ and ${ }^{222} \mathrm{Rn}$ respectively) which are present in air, so radon diffusion from the laboratory air as well as radon emanation from materials must be controlled. Another possible external source of background are neutrons, whether produced by natural radioactivity in the walls or shielding or as secondary products of cosmic muons; preliminary estimations seem to point that these contributions are very much below the level of concern for NEXT. Also high energy gammas can be produced in muon-induced electromagnetic cascades; although they seem to be of no importance for NEXT, they could be partially tagged by an active muon veto in the shielding.

Consequently, the activity of the lower part of ${ }^{232} \mathrm{Th}$ and ${ }^{238} \mathrm{U}$ chains $\left({ }^{208} \mathrm{Tl}\right.$ and ${ }^{214} \mathrm{Bi}$ isotopes $)$ from the components of the set-up and at the laboratory is the main concern in NEXT. According to the NEXT-100 design, the list of the main materials subject to radiopurity control and the target radiopurity for each of them were established (see table 3 in [3]). The relevant materials for the different parts of the experimental set-up to be considered include: lead and copper for shielding; stainless steel and inconel for vessel; PEEK (PolyEther Ether Ketone), polyethylene and coating materials for High Voltage (HV) and electroluminescence components; photomultipliers, windows, printed circuit boards and other electronic components (capacitors, resistors, cables...) for the energy and tracking planes. The target sensitivity was fixed following results from the literature and from the first measurements made for NEXT.

In this paper, the initial material radiopurity control performed for the NEXT experiment is presented. First, in Sec. 2 the techniques and equipment used to carry out the measurements of activity levels are described. Then, the results obtained for all the analyzed materials are shown and discussed in Sec. 3 .

\section{Techniques and equipment}

The techniques employed for the radiopurity measurements for NEXT are Glow-Discharge Mass Spectrometry (GDMS) and gamma-ray spectroscopy using ultra-low background germanium detectors operated deep underground. Each one has advantages and drawbacks, which make them more or less suitable depending on the context.

\subsection{GDMS}

In GDMS, the sample to be analyzed forms the cathode in a plasma or discharge gas, typically argon. Argon ions are accelerated toward the sample resulting in erosion and atomization of its surface. The sputtered species are transported into the plasma where they are ionized. Ions are then extracted for mass spectrometry. This method is consequently very suitable for metals. Similarly to other techniques also based on mass spectrometry, it is fast and requires only a small sample of the 
material (typically, samples with a surface of $2 \times 2 \mathrm{~cm}^{2}$ were prepared for NEXT measurements). However, the output given is normally only the concentration of elements while particular isotopes are not identified. Measured concentrations of $\mathrm{U}$, Th and $\mathrm{K}$ have been converted to ${ }^{232} \mathrm{Th},{ }^{238} \mathrm{U}$ and ${ }^{40} \mathrm{~K}$ activities ${ }^{1}$. Having no information on daughter nuclides in the chains, a possible disequilibrium cannot be detected. In any case, this technique can be very helpful to make a pre-selection of samples to be later screened with germanium detectors underground. GDMS measurements for NEXT materials were made by Shiva Technologies (Evans Analytical Group ${ }^{2}$ ) in France.

\subsection{Germanium gamma-ray spectrometry}

The most important advantage of gamma-ray spectrometry performed with germanium detectors is that, being non-destructive, the actual components to be used in experiments can be examined. Germanium detectors offer very good energy resolution and low intrinsic background. In addition, activities of isotopes dangerous for the experiment background are directly assessed. No sample pre-treatment is necessary, but massive samples and time-consuming measurements (lasting up to several weeks) are needed to quantify very low activities.

The LSC offers a Radiopurity Service ${ }^{3}$ to measure ultra-low level radioactivity using several germanium detectors operated at the Hall C for gamma-ray spectroscopy (see figure 21); it is intended to support the construction of experiments to be operated there. Since the laboratory is located at a depth of 2450 m.w.e., the cosmic muon flux is about 5 orders of magnitude lower than at sea-level surface. Radon activity in the air is between 50 and $80 \mathrm{~Bq} / \mathrm{m}^{3}$ in the underground halls [23]. All germanium spectroscopy measurements presented here were carried out at LSC using in particular four different $\sim 2.2 \mathrm{~kg}$ detectors from LSC and a $\sim 1 \mathrm{~kg}$ detector from the University of Zaragoza.

- The detectors property of LSC are p-type close-end coaxial High Purity germanium detectors produced by Canberra France with 100-110\% relative efficiencies ${ }^{4}$ and a FWHM energy resolution of $\sim 2 \mathrm{keV}$ at the ${ }^{60} \mathrm{Co}$ gamma line of $1332 \mathrm{keV}$. The active volume of crystals ranges from 410 to $420 \mathrm{~cm}^{3}$ and cryostats are made of ultra-low background aluminum. The data acquisition system is based on Digital Signal Processing using Canberra DSA1000 modules. Each detector has a shield consisting of $5 \mathrm{~cm}$ of oxygen-free copper and $20 \mathrm{~cm}$ of very low activity lead having $<30 \mathrm{mBq} / \mathrm{kg}$ of ${ }^{210} \mathrm{~Pb}$; nitrogen gas is flushed inside a methacrylate box to avoid airborne radon intrusion. The detectors used for NEXT measurements are those named GeOroel, GeTobazo, GeAnayet and GeLatuca; they are in operation since 2011.

- The detector from University of Zaragoza, named Paquito, is also a p-type close-end coaxial High Purity germanium detector, but with a smaller crystal volume of $190 \mathrm{~cm}^{3}$ inside a copper cryostat. The FWHM energy resolution at $1332 \mathrm{keV}$ is $2.7 \mathrm{keV}$. It is operated inside a shield made of $10 \mathrm{~cm}$ of archaeological lead plus $15 \mathrm{~cm}$ of low activity lead with nitrogen

\footnotetext{
${ }^{1}$ Conversion factors are: $1 \mathrm{ppb} \mathrm{U}=12.4 \mathrm{mBq} / \mathrm{kg}{ }^{238} \mathrm{U}, 1 \mathrm{ppb} \mathrm{Th}=4.1 \mathrm{mBq} / \mathrm{kg}{ }^{232} \mathrm{Th}$ and $1 \mathrm{ppm}{ }^{\text {nat }} \mathrm{K}=31 \mathrm{mBq} / \mathrm{kg}$ ${ }^{40} \mathrm{~K}$.

${ }^{2} \mathrm{http} / / / \mathrm{www}$. eaglabs.com

${ }^{3}$ http://www.lsc-canfranc.es/en/for-users/lsc-services/radiopurity.html

${ }^{4}$ Efficiency relative to a $3^{\prime \prime} \times 3^{\prime \prime} \mathrm{NaI}$ detector at $1332 \mathrm{keV}$ and for a distance of $25 \mathrm{~cm}$ between source and detector.
} 


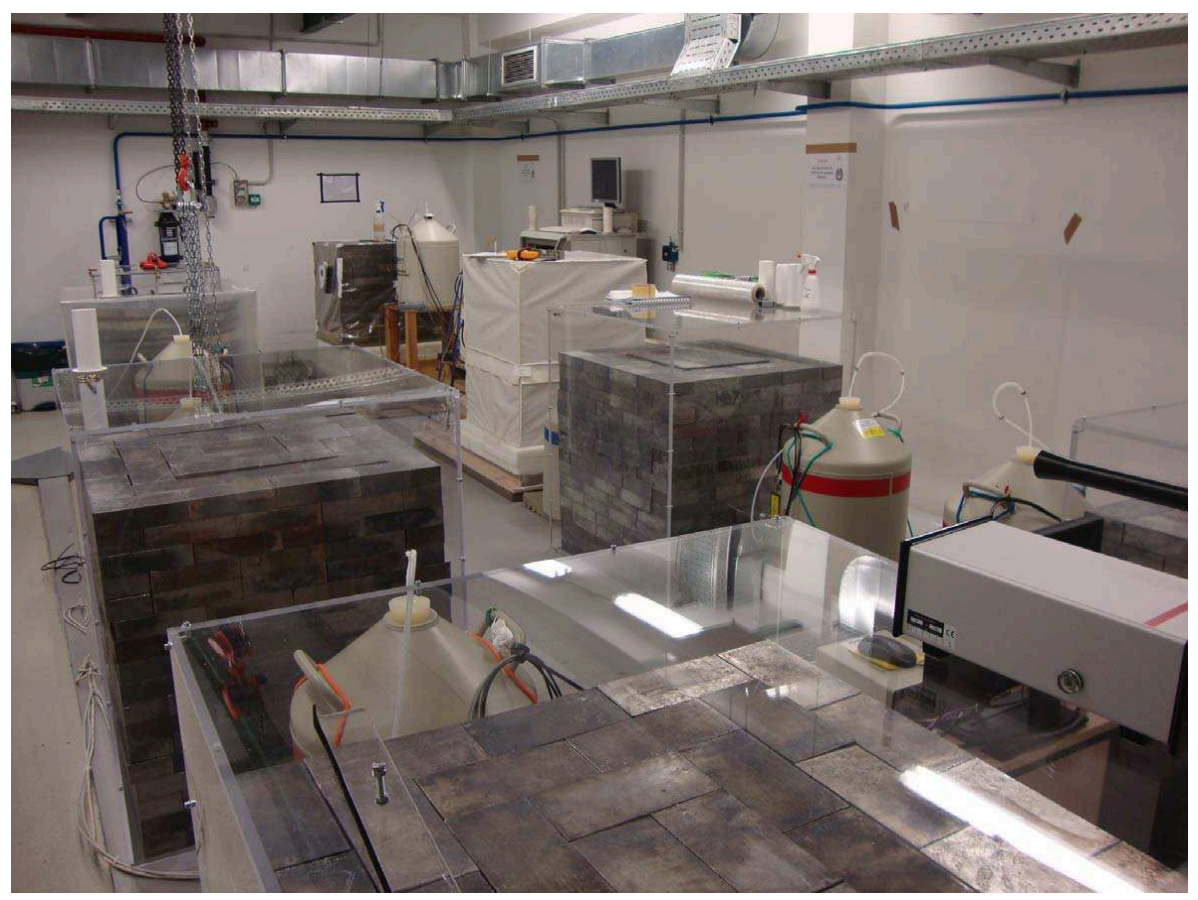

Figure 2. Picture of the Hall C of the LSC where several germanium detectors inside their shieldings are operated for material radiopurity screening (courtesy of LSC). Background counting rates are reported in table 1 .

flush too. The electronic chain for data acquisition is based on standard Canberra 2020 Linear Amplifier and Canberra 8075 Analog-to-Digital-Converter modules. This detector has been used for radiopurity measurements at Canfranc for several years (more details can be found in [24]).

The background of each detector inside its shielding is determined by taking data with no sample for long periods of time of at least one month, due to the low counting rates. Table 1 shows the counting rates of all the detectors used in the NEXT measurements in the energy window from 100 to $2700 \mathrm{keV}$ and at different peaks: $583 \mathrm{keV}$ from ${ }^{208} \mathrm{Tl}, 609 \mathrm{keV}$ from ${ }^{214} \mathrm{Bi}$ and 1461 $\mathrm{keV}$ from ${ }^{40} \mathrm{~K}$; all the rates are expressed in counts per day and per $\mathrm{kg}$ of germanium detector and correspond to background measurements performed from May to July 2012. The complete background spectrum of GeOroel detector, registered for 38.00 days, is presented in figure 3 . Lines from cosmogenic isotopes like ${ }^{54} \mathrm{Mn},{ }^{58} \mathrm{Co}$ and ${ }^{65} \mathrm{Zn}$, having half-lives around one year, are still observable in GeOroel detector but not in the other ones.

To derive the activity in a sample of an isotope producing a gamma emission of a certain energy, the main ingredients (together with the time of the measurement and the branching ratio of the emission) are the net signal (that is, the number of events at the gamma line due to the sample) and the full-energy peak detection efficiency at the corresponding energy.

In the context of determining ultra-low activities of a sample (at the level of $\mathrm{mBq} / \mathrm{kg}$ and below), when comparing the measured energy spectrum of the sample with that of the detector background, it is not straightforward to decide if the gross signal can be considered to statistically 
Table 1. Background counting rates (expressed in counts $\mathrm{d}^{-1} \mathrm{~kg}^{-1}$ ) of the germanium detectors used at LSC for the NEXT measurements. Integral rate from 100 to $2700 \mathrm{keV}$ and rates at different peaks (583 keV from ${ }^{208} \mathrm{Tl}, 609 \mathrm{keV}$ from ${ }^{214} \mathrm{Bi}$ and $1461 \mathrm{keV}$ from ${ }^{40} \mathrm{~K}$ ) are presented. Only statistical errors are quoted.

\begin{tabular}{lccccc}
\hline Detector name & Mass $(\mathrm{kg})$ & $100-2700 \mathrm{keV}$ & $583 \mathrm{keV}$ & $609 \mathrm{keV}$ & $1461 \mathrm{keV}$ \\
\hline GeOroel & 2.230 & $490 \pm 2$ & $0.8 \pm 0.1$ & $3.0 \pm 0.2$ & $0.41 \pm 0.07$ \\
GeAnayet & 2.183 & $714 \pm 3$ & $3.8 \pm 0.2$ & $1.7 \pm 0.1$ & $0.38 \pm 0.07$ \\
GeTobazo & 2.185 & $708 \pm 3$ & $4.0 \pm 0.2$ & $1.3 \pm 0.1$ & $0.40 \pm 0.06$ \\
GeLatuca & 2.187 & $710 \pm 3$ & $3.3 \pm 0.2$ & $5.9 \pm 0.3$ & $0.56 \pm 0.08$ \\
Paquito & 1 & $79 \pm 2$ & $0.27 \pm 0.09$ & $0.5 \pm 0.1$ & $0.25 \pm 0.09$ \\
\hline
\end{tabular}

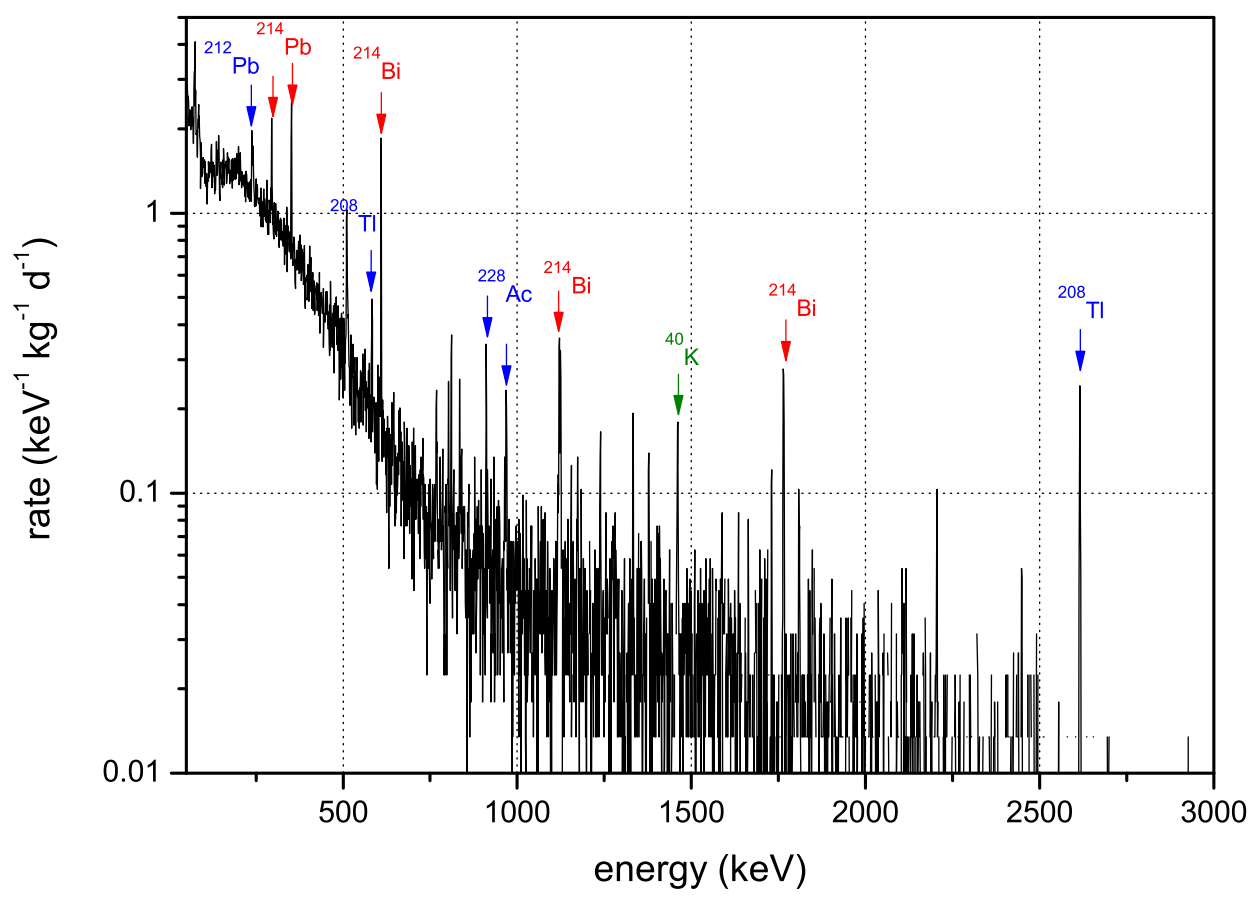

Figure 3. Energy spectrum of GeOroel detector at LSC registered in a background measurement for 38.00 days. Main gamma lines from isotopes of the ${ }^{238} \mathrm{U}$ (red) and ${ }^{232} \mathrm{Th}$ (blue) radioactive chains and from ${ }^{40} \mathrm{~K}$ (green) are marked.

differ from the background signal. The criteria proposed in Currie's landmark paper [25] and more recently revised in [16, 26] have been followed here. Activities have been quantified when possible and upper limits with a $95.45 \%$ C.L. have been derived otherwise.

Concerning the estimate of the detection efficiency, Monte Carlo simulations based on the Geant4 [27] code have been performed for each sample, accounting for intrinsic efficiency, the geometric factor and self-absorption at the sample. No relevant change has been observed in the Geant 4 simulation when changing version or the physical models implemented for interactions (considering the low energy extensions for electromagnetic processes based on theoretical models and on exploitation of evaluated data, G4EmLivermorePhysics class and the previous G4LowEnergy* 


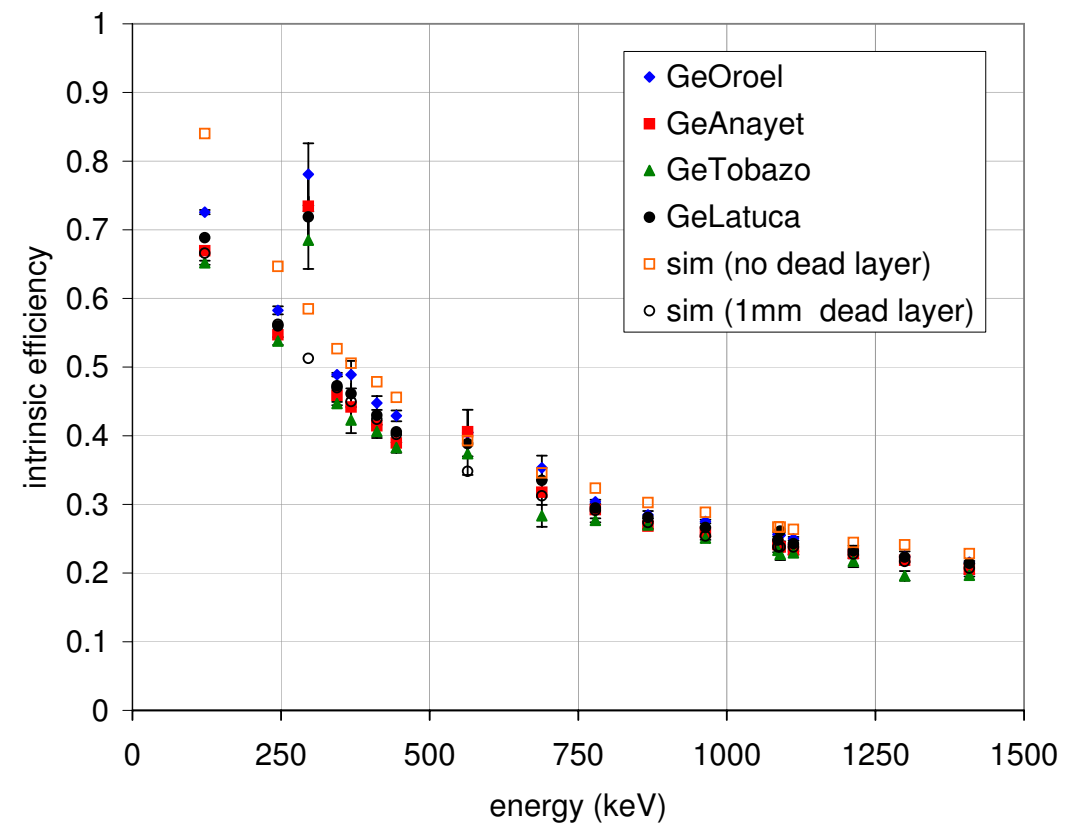

Figure 4. Intrinsic efficiency measured for different Ge detectors using a ${ }^{152}$ Eu reference source and the corresponding simulation, considering a 1-mm-thick crystal dead layer or no dead layer.

classes [28]). Validation of the simulation has been made by comparing the efficiency curve of the detectors measured with a ${ }^{152} \mathrm{Eu}$ reference source of known activity located at $25 \mathrm{~cm}$ from the detector with the simulated one. Figure $\bigoplus$ shows the intrinsic efficiency (corrected by solid angle) obtained for GeOroel, GeTobazo, GeAnayet and GeLatuca detectors together with the corresponding simulations for GeTobazo/GeAnayet. The higher efficiency shown by GeOroel is due to a slightly larger volume in comparison with the other detectors. The inclusion of a 1-mm-thick dead layer in the simulation has improved the agreement with measurements, especially at low energies, reducing deviations to a level of 5\%; an overall uncertainty of $10 \%$ is considered for the simulated detection efficiency of the samples and propagated to the final activity value. The larger discrepancy observed in figure $\bigoplus$ for $295 \mathrm{keV}$ values is due to the interference in the measurements at this energy of the gamma line of ${ }^{214} \mathrm{~Pb}$, descendant of ${ }^{222} \mathrm{Rn}$ present in air (measurements with the ${ }^{152} \mathrm{Eu}$ source were carried out with the shields partially open and no background substraction was made). The relative efficiencies derived from these measurements and also from the simulation reproduce the values specified by the manufacturer.

Activities of different sub-series in the natural chains of ${ }^{238} \mathrm{U},{ }^{232} \mathrm{Th}$ and ${ }^{235} \mathrm{U}$ as well as of common primordial, cosmogenic or anthropogenic radionuclides like ${ }^{40} \mathrm{~K},{ }^{60} \mathrm{Co}$ and ${ }^{137} \mathrm{Cs}$ have been evaluated by analyzing the most intense gamma lines of different isotopes. Outgassing and chemical procedures in materials can make secular equilibrium in radioactive chains break, so information provided by germanium detectors at the different stages is very important. For ${ }^{238} \mathrm{U}$, emissions from ${ }^{234} \mathrm{Th}$ and ${ }^{234 m} \mathrm{~Pa}$ are searched to quantify activity of the upper part of the chain and lines from ${ }^{214} \mathrm{~Pb}$ and ${ }^{214} \mathrm{Bi}$ for the sub-chain starting with ${ }^{226} \mathrm{Ra}$ up to ${ }^{210} \mathrm{~Pb}$. For ${ }^{232} \mathrm{Th}$ chain, 
emissions of ${ }^{228} \mathrm{Ac}$ are analyzed for the upper part and those of ${ }^{212} \mathrm{~Pb},{ }^{212} \mathrm{Bi}$ and ${ }^{208} \mathrm{Tl}$ for the lower one. Concerning ${ }^{235} \mathrm{U}$ chain, only emissions from the parent isotope are taken into account since all the other ones have very low intensities.

\section{Measurements and results}

Materials of very massive components and of those to be located inside the detector vessel have been selected for the first screening campaign of NEXT, trying to keep up with the schedule of construction of several subsystems like the pressure vessel, the field cage and the boards for the tracking plane. The performed measurements are described and discussed in the context of NEXT. Details concerning the detector used, the size of the sample and the time of data taking for all measurements using germanium detectors are presented in table 2. The results obtained are all independently summarized in table 3; reported errors correspond to $1 \sigma$ uncertainties including both statistical and efficiency uncertainties. 
Table 2. Information on the germanium gamma-ray spectrometry measurements performed for NEXT at LSC: material, detector used, samples size (mass, area or number of pieces) and screening time. The corresponding row number of table 3 where the activity values obtained for each sample are reported is also quoted.

\begin{tabular}{|c|c|c|c|c|}
\hline Material, Supplier & $\#$ in table 3 & Detector & Sample size & Screening time $(\mathrm{d})$ \\
\hline $\mathrm{Pb}$, Tecnibusa & 5 & GeAnayet & $5585 \mathrm{~g}$ & 19.44 \\
\hline $\mathrm{Pb}$, Tecnibusa & 6 & GeAnayet & $5585 \mathrm{~g}$ & 35.99 \\
\hline $\mathrm{Cu}$, Luvata & 10 & Paquito & $681 \mathrm{~g}$ & 39.17 \\
\hline Ti, SMP & 11 & GeOroel & $121 \mathrm{~g}$ & 38.46 \\
\hline Ti, SMP & 12 & GeTobazo & $121 \mathrm{~g}$ & 43.11 \\
\hline Ti, Ti Metal Supply & 13 & GeOroel & $1804 \mathrm{~g}$ & 47.23 \\
\hline 304L Stainless Steel, Pfeiffer & 14 & Paquito & $347 \mathrm{~g}$ & 19.55 \\
\hline 316Ti Stainless Steel, $10 \mathrm{~mm}$, Nironit & 15 & GeTobazo & $7684 \mathrm{~g}$ & 33.00 \\
\hline 316Ti Stainless Steel, $15 \mathrm{~mm}$, Nironit & 16 & GeTobazo & $10205 \mathrm{~g}$ & 35.61 \\
\hline 316Ti Stainless Steel, $50 \mathrm{~mm}$, Nironit & 17 & GeAnayet & $4816 \mathrm{~g}$ & 34.72 \\
\hline Inconel 625, Mecanizados Kanter & 18 & GeTobazo & $1004 \mathrm{~g}$ & 27.98 \\
\hline Inconel 718, Mecanizados Kanter & 19 & GeOroel & $611 \mathrm{~g}$ & 27.93 \\
\hline PEEK, Sanmetal & 20 & Paquito & $459 \mathrm{~g}$ & 24.27 \\
\hline Polyethylene, IN2 Plastics & 21 & GeAnayet & $1315 \mathrm{~g}$ & 36.76 \\
\hline Semitron ES225, Quadrant EPP & 22 & GeOroel & $1618 \mathrm{~g}$ & 35.05 \\
\hline SMD resistor, Farnell & 23 & Paquito & $50 \mathrm{pc}$ & 18.15 \\
\hline SM5D resistor, Finechem & 24 & Paquito & $100 \mathrm{pc}$ & 31.45 \\
\hline Kapton-Cu PCB, LabCircuits & 25 & Paquito & $260.15 \mathrm{~cm}^{2}$ & 35.28 \\
\hline Cuflon, Polyflon & 26 & GeOroel & $1876 \mathrm{~g}$ & 24.29 \\
\hline Bonding films, Polyflon & 27 & GeAnayet & $288 \mathrm{~g}$ & 30.83 \\
\hline FFC/FCP connector, Hirose & 28 & Paquito & $19 \mathrm{pc}(1.23 \mathrm{~g} / \mathrm{pc})$ & 6.83 \\
\hline P5K connector, Panasonic & 29 & Paquito & $15 \mathrm{pc}(0.67 \mathrm{~g} / \mathrm{pc})$ & 7.58 \\
\hline Thermoplastic connector, Molex & 30 & GeLatuca & $29 \mathrm{pc}(0.53 \mathrm{~g} / \mathrm{pc})$ & 17.20 \\
\hline Solder paste, Multicore & 31 & GeLatuca & $457 \mathrm{~g}$ & 44.30 \\
\hline Solder wire, Multicore & 32 & Paquito & $91 \mathrm{~g}$ & 7.74 \\
\hline Ta capacitor, Vishay Sprague & 33 & GeAnayet & $277 \mathrm{pc}(0.64 \mathrm{~g} / \mathrm{pc})$ & 17.97 \\
\hline
\end{tabular}




\begin{tabular}{|c|c|c|c|c|c|c|c|c|c|c|c|c|}
\hline$\#$ & Material & Supplier & Technique & Unit & ${ }^{238} \mathbf{U}$ & ${ }^{226} \mathbf{R a}$ & ${ }^{232} \mathbf{T h}$ & ${ }^{228} \mathbf{T h}$ & ${ }^{235} \mathbf{U}$ & ${ }^{40} \mathbf{K}$ & ${ }^{60} \mathrm{Co}$ & ${ }^{137} \mathrm{Cs}$ \\
\hline & Shielding & & & & & & & & & & & \\
\hline 1 & $\mathrm{~Pb}$ & Cometa & GDMS & $\mathrm{mBq} / \mathrm{kg}$ & 0.37 & & 0.073 & & & $<0.31$ & & \\
\hline 2 & $\mathrm{~Pb}$ & Mifer & GDMS & $\mathrm{mBq} / \mathrm{kg}$ & $<1.2$ & & $<0.41$ & & & 0.31 & & \\
\hline 3 & $\mathrm{~Pb}$ & Mifer & GDMS & $\mathrm{mBq} / \mathrm{kg}$ & 0.33 & & 0.10 & & & 1.2 & & \\
\hline 4 & $\mathrm{~Pb}$ & Tecnibusa & GDMS & $\mathrm{mBq} / \mathrm{kg}$ & 0.73 & & 0.14 & & & 0.91 & & \\
\hline 5 & $\mathrm{~Pb}$ & Tecnibusa & $\mathrm{Ge}$ & $\mathrm{mBq} / \mathrm{kg}$ & $<94$ & $<2.0$ & $<3.8$ & $<4.4$ & $<30$ & $<2.8$ & $<0.2$ & $<0.8$ \\
\hline 6 & $\mathrm{~Pb}$ & Tecnibusa & $\mathrm{Ge}$ & $\mathrm{mBq} / \mathrm{kg}$ & $<57$ & $<1.9$ & $<1.7$ & $<2.8$ & $<22$ & $<1.7$ & $<0.1$ & $<0.5$ \\
\hline 7 & $\mathrm{Cu}(\mathrm{ETP})$ & Sanmetal & GDMS & $\mathrm{mBq} / \mathrm{kg}$ & $<0.062$ & & $<0.020$ & & & & & \\
\hline 8 & $\mathrm{Cu}(\mathrm{C} 10100)$ & Luvata (hot rolled) & GDMS & $\mathrm{mBq} / \mathrm{kg}$ & $<0.012$ & & $<0.0041$ & & & 0.061 & & \\
\hline 9 & $\mathrm{Cu}(\mathrm{C} 10100)$ & Luvata (cold rolled) & GDMS & $\mathrm{mBq} / \mathrm{kg}$ & $<0.012$ & & $<0.0041$ & & & 0.091 & & \\
\hline \multirow[t]{2}{*}{10} & $\mathrm{Cu}(\mathrm{C} 10100)$ & Luvata (hot+cold rolled) & $\mathrm{Ge}$ & $\mathrm{mBq} / \mathrm{kg}$ & & $<7.4$ & $<0.8$ & $<4.3$ & & $<18$ & $<0.8$ & $<1.2$ \\
\hline & Vessel & & & & & & & & & & & \\
\hline 11 & $\mathrm{Ti}$ & SMP & $\mathrm{Ge}$ & $\mathrm{mBq} / \mathrm{kg}$ & $<233$ & $<5.7$ & $<8.8$ & $<9.5$ & $3.4 \pm 1.0$ & $<22$ & $<3.3$ & $<5.2$ \\
\hline 12 & $\mathrm{Ti}$ & SMP & $\mathrm{Ge}$ & $\mathrm{mBq} / \mathrm{kg}$ & $<361$ & $<6.6$ & $<11$ & $<10$ & $<8.0$ & $<15$ & $<1.0$ & $<1.8$ \\
\hline 13 & $\mathrm{Ti}$ & Ti Metal Supply & $\mathrm{Ge}$ & $\mathrm{mBq} / \mathrm{kg}$ & $<14$ & $<0.22$ & $<0.5$ & $3.6 \pm 0.2$ & $0.43 \pm 0.08$ & $<0.6$ & $<0.07$ & $<0.07$ \\
\hline 14 & 304L SS & Pfeiffer & $\mathrm{Ge}$ & $\mathrm{mBq} / \mathrm{kg}$ & & $14.3 \pm 2.8$ & $9.7 \pm 2.3$ & $16.2 \pm 3.9$ & $3.2 \pm 1.1$ & $<17$ & $11.3 \pm 2.7$ & $<1.6$ \\
\hline 15 & 316Ti SS & Nironit, $10-\mathrm{mm}$-thick & $\mathrm{Ge}$ & $\mathrm{mBq} / \mathrm{kg}$ & $<21$ & $<0.57$ & $<0.59$ & $<0.54$ & $<0.74$ & $<0.96$ & $2.8 \pm 0.2$ & $<0.12$ \\
\hline 16 & 316Ti SS & Nironit, 15 -mm-thick & $\mathrm{Ge}$ & $\mathrm{mBq} / \mathrm{kg}$ & $<25$ & $<0.46$ & $<0.69$ & $<0.88$ & $<0.75$ & $<1.0$ & $4.4 \pm 0.3$ & $<0.17$ \\
\hline 17 & 316Ti SS & Nironit, 50-mm-thick & $\mathrm{Ge}$ & $\mathrm{mBq} / \mathrm{kg}$ & $67 \pm 22$ & $<1.7$ & $2.1 \pm 0.4$ & $2.0 \pm 0.7$ & $2.4 \pm 0.6$ & $<2.5$ & $4.2 \pm 0.3$ & $<0.6$ \\
\hline 18 & Inconel 625 & Mecanizados Kanter & $\mathrm{Ge}$ & $\mathrm{mBq} / \mathrm{kg}$ & $<120$ & $<1.9$ & $<3.4$ & $<3.2$ & $<4.6$ & $<3.9$ & $<0.4$ & $<0.6$ \\
\hline \multirow[t]{2}{*}{19} & Inconel 718 & Mecanizados Kanter & $\mathrm{Ge}$ & $\mathrm{mBq} / \mathrm{kg}$ & $309 \pm 78$ & $<3.4$ & $<5.1$ & $<4.4$ & $15.0 \pm 1.9$ & $<13$ & $<1.4$ & $<1.3$ \\
\hline & HV, EL components & & & & & & & & & & & \\
\hline 20 & PEEK & Sanmetal & $\mathrm{Ge}$ & $\mathrm{mBq} / \mathrm{kg}$ & & $36.3 \pm 4.3$ & $14.9 \pm 5.3$ & $11.0 \pm 2.4$ & $<7.8$ & $8.3 \pm 3.0$ & $<3.3$ & $<2.6$ \\
\hline 21 & Polyethylene & IN2 Plastics & $\mathrm{Ge}$ & $\mathrm{mBq} / \mathrm{kg}$ & $<140$ & $<1.9$ & $<3.8$ & $<2.7$ & $<1.0$ & $<8.9$ & $<0.5$ & $<0.5$ \\
\hline 22 & Semitron ES225 & Quadrant EPP & $\mathrm{Ge}$ & $\mathrm{mBq} / \mathrm{kg}$ & $<101$ & $<2.3$ & $<2.0$ & $<1.8$ & $1.8 \pm 0.3$ & $513 \pm 52$ & $<0.5$ & $<0.6$ \\
\hline 23 & SMD resistor & Farnell & $\mathrm{Ge}$ & $\mathrm{mBq} / \mathrm{pc}$ & $2.3 \pm 1.0$ & $0.16 \pm 0.03$ & $0.30 \pm 0.06$ & $0.30 \pm 0.05$ & $<0.05$ & $0.19 \pm 0.08$ & $<0.02$ & $<0.03$ \\
\hline \multirow[t]{2}{*}{24} & SM5D resistor & Finechem & $\mathrm{Ge}$ & $\mathrm{mBq} / \mathrm{pc}$ & $0.4 \pm 0.2$ & $0.022 \pm 0.007$ & $<0.023$ & $<0.016$ & $0.012 \pm 0.005$ & $50.17 \pm 0.07$ & $<0.005$ & $<0.005$ \\
\hline & Energy, tracking plane & & & & & & & & & & & \\
\hline 25 & Kapton-Cu PCB & LabCircuits & $\mathrm{Ge}$ & $\mathrm{mBq} / \mathrm{cm}^{2}$ & $<0.26$ & $<0.014$ & $<0.012$ & $<0.008$ & $<0.002$ & $<0.040$ & $<0.002$ & $<0.002$ \\
\hline 26 & Cuflon & Polyflon & $\mathrm{Ge}$ & $\mathrm{mBq} / \mathrm{kg}$ & $<33$ & $<1.3$ & $<1.1$ & $<1.1$ & $<0.6$ & $4.8 \pm 1.1$ & $<0.3$ & $<0.3$ \\
\hline 27 & Bonding films & Polyflon & $\mathrm{Ge}$ & $\mathrm{mBq} / \mathrm{kg}$ & $1140 \pm 300$ & $487 \pm 23$ & $79.8 \pm 6.6$ & $66.0 \pm 4.8$ & $60.0 \pm 5.5$ & $832 \pm 87$ & $<4.4$ & $<3.8$ \\
\hline 28 & FFC/FCP connector & Hirose & $\mathrm{Ge}$ & $\mathrm{mBq} / \mathrm{pc}$ & $<50$ & $4.6 \pm 0.7$ & $6.5 \pm 1.2$ & $6.4 \pm 1.0$ & $<0.75$ & $3.9 \pm 1.4$ & $<0.2$ & $<0.5$ \\
\hline 29 & $\begin{array}{l}\text { P5K connector } \\
\text { (Follows at next page) }\end{array}$ & Panasonic & $\mathrm{Ge}$ & $\mathrm{mBq} / \mathrm{pc}$ & $<42$ & $6.0 \pm 0.9$ & $9.5 \pm 1.7$ & $9.4 \pm 1.4$ & $<0.95$ & $4.1 \pm 1.5$ & $<0.2$ & $<0.8$ \\
\hline
\end{tabular}




\begin{tabular}{|c|c|c|c|c|c|c|c|c|c|c|c|c|}
\hline$\#$ & Material & Supplier & Technique & Unit & ${ }^{238} \mathbf{U}$ & ${ }^{226} \mathbf{R a}$ & ${ }^{232} \mathbf{T h}$ & ${ }^{228} \mathbf{T h}$ & ${ }^{235} \mathbf{U}$ & ${ }^{40} \mathbf{K}$ & ${ }^{60} \mathrm{Co}$ & ${ }^{137} \mathbf{C s}$ \\
\hline 30 & Thermopl. connector & Molex & $\mathrm{Ge}$ & $\mathrm{mBq} / \mathrm{pc}$ & $<7.3$ & $1.77 \pm 0.08$ & $3.01 \pm 0.19$ & $2.82 \pm 0.15$ & $<0.31$ & $2.12 \pm 0.25$ & $<0.022$ & $0.27 \pm 0.03$ \\
\hline 31 & Solder paste & Multicore & $\mathrm{Ge}$ & $\mathrm{mBq} / \mathrm{kg}$ & $<310$ & $<4.9$ & $<8.0$ & $<6.0$ & $<5.2$ & $<13$ & $<1.0$ & $<1.6$ \\
\hline 32 & Solder wire & Multicore & $\mathrm{Ge}$ & $\mathrm{mBq} / \mathrm{kg}$ & $<4900$ & $(7.7 \pm 1.2) 10^{2}$ & ${ }^{2}<147$ & $<14$ & & $<257$ & $<30$ & $<36$ \\
\hline 33 & Ta capacitor & Vishay Sprague & $\mathrm{Ge}$ & $\mathrm{mBq} / \mathrm{pc}$ & $<0.8$ & $0.043 \pm 0.003$ & $30.034 \pm 0.00$ & $0.032 \pm 0.00$ & $<0.010$ & & $<0.002$ & $<0.003$ \\
\hline
\end{tabular}

Table 3: Activities measured in relevant materials for NEXT and following dif-

ferent techniques. GDMS results were derived from $\mathrm{U}$, Th and $\mathrm{K}$ concentrations.

Germanium gamma-ray spectrometry results reported for ${ }^{238} \mathrm{U}$ and ${ }^{232} \mathrm{Th}$ corre-

spond to the upper part of the chains and those of ${ }^{226} \mathrm{Ra}$ and ${ }^{228} \mathrm{Th}$ give activities

of the lower parts (see text). 
For the metal samples prepared for germanium spectrometry, a standard cleaning protocol was followed including the following steps: diamond cut, cleaning with acetone (alcohol was avoided because it may affect their mechanical properties), ultrasound bath with acid-detergent, $63 \%$ nitric acid bath, new cleaning with acetone and storing in a sealed plastic bag. Other samples were cleaned in an ultrasonic bath and with pure alcohol.

In the following, results are presented and discussed for the different screened materials grouped according to their position in the detector set-up.

\subsection{Shielding}

The external passive shielding for NEXT-100 will be made of lead bricks forming a 20-cm-thick lead castle and there will be also an additional 12-cm-thick inner layer of copper to attenuate the radiation originated in the vessel material [3]. Copper is expected to shield in-vessel electronics components if necessary and for the photomultipliers enclosures too.

Lead samples from different suppliers (Mifer ${ }^{5}$, using two different raw materials, and Tecnibusa $^{6}$ from Spain and COMETA ${ }^{7}$ from Italy) were screened by GDMS. Results are shown in rows \#1-4 of table 3; it must be noted that the quantified $U$ and Th concentrations were reported to be at the ultimate limit of detection. The results obtained for COMETA lead are in agreement with the specifications given by the company. Since a large amount of the lead bricks will be ultimately provided by Tecnibusa, two different half-brick samples $\left(10 \times 10 \times 5 \mathrm{~cm}^{3}\right.$ each) from this company were measured at LSC; results are presented in rows \#5-6 of table 3. This lead has a low activity of ${ }^{210} \mathrm{~Pb}$ at the level of some tens of $\mathrm{Bq} / \mathrm{kg}$. $\mathrm{U}$ and $\mathrm{Th}$ contamination in lead are normally not very important [6], since radioactive contaminants are effectively removed from lead together with silver [29]. For instance, for Dow Run lead produced by JL Goslar ${ }^{8}$, activities of tens of $\mu \mathrm{Bq} / \mathrm{kg}$ were measured in [11] and even lower values have been presented by EXO [12] and GERDA [13] experiments as upper limits.

Three copper samples having different origins were also screened by GDMS. One is Electrolytic Tough Pitch (ETP) copper supplied by the Spanish company Sanmetal ${ }^{9}$ while the other two were made of $\mathrm{C} 10100$ copper from the Luvata company ${ }^{10}$, having different production mechanism (hot versus cold rolling). The Luvata copper samples were screened together using the Paquito detector as well. All results on copper are shown in rows \#7-10 of table 3 . The upper bounds on activities derived from the germanium spectrometry measurement were much less stringent than those from GDMS due to its limited sensitivity; hence a new measurement, with much more mass and time and using a bigger germanium detector is foreseen. The cleanest copper we are aware of is that supplied by Norddeutsche Affinerie (Germany) ${ }^{11}$; very low upper limits for its activity were set in measurements at the Gran Sasso Underground Laboratory [11] and by the EXO Collaboration [12] and even activity from the natural chains and ${ }^{40} \mathrm{~K}$ was quantified by the XENON

\footnotetext{
${ }^{5}$ http://www.mifer.com

${ }^{6} \mathrm{http} / / / \mathrm{www}$. tecnibusa.com

${ }^{7} \mathrm{http} / / / \mathrm{www}$ fonderiaroma.com

${ }^{8} \mathrm{http}: / / \mathrm{www}$. doerun.com, http://www.jlgoslar.de

${ }^{9} \mathrm{http} / / / \mathrm{www} \cdot$ sanmetal.es

${ }^{10} \mathrm{http} / / / \mathrm{www}$. luvata.com

${ }^{11}$ Now re-branded as Aurubis, http://www.aurubis.com
} 
experiment [17], at levels of a few tens of $\mu \mathrm{Bq} / \mathrm{kg}$. Although the GDMS measurement of Luvata copper has given information only on $U$ and Th concentration, the upper limits derived are at the same level or even better than the results for the Norddeutsche Affinerie copper, and Luvata copper has therefore been chosen as the first option for the NEXT shield.

\subsection{Vessel}

The pressure vessel of NEXT-100 must be able to hold 15 bar of xenon. It consists of a cylindrical center section (barrel) with two identical torispherical heads on each end [3]. The vessel orientation is horizontal, so as to minimize the overall height. Although it will be ultimately made of stainless steel, the first considered option was titanium, so several samples of both materials have been screened. Inconel (nickel-chromium alloy) will be used to bolt the end-caps to the main body due to its excellent strength properties and therefore its radiopurity has been analyzed too.

Grade 2 titanium was initially proposed to be used for the main components of the vessel. Two samples were screened at LSC, one from a Spanish supplier, Titanio SMP ${ }^{12}$ and the other from Titanium Metal Supply ${ }^{13}$. Results are shown in rows \#11-13 of table 3. The Ti SMP sample was screened using two different germanium detectors, GeOroel (row \#11) and GeTobazo (row \#12) as a cross-check exercise; the small differences found can be well understood taking into account the differences in the background rates of the detectors in several energy ranges. Thanks to the much larger mass available in the sample, upper limits on activities derived for the Ti Metal Supply sample are much lower than for the Ti SMP sample and it has been possible to quantify the activity of the lower part of the ${ }^{232} \mathrm{Th}$ chain. Production of ${ }^{46} \mathrm{Sc}$, beta emitter with $\mathrm{Q}=2366.7 \mathrm{keV}$ and $\mathrm{T}_{1 / 2}=83.8$ days, has been also observed for this sample; it must have been generated by $(\mathrm{n}, \mathrm{p})$ reactions on ${ }^{46} \mathrm{Ti}$ induced by fast neutrons. The LUX collaboration has carried out an exhaustive analysis of Ti samples [30], obtaining different levels of radiopurity for them; the presence of ${ }^{46} \mathrm{Sc}$ is usually identified.

A great deal of activity measurements for different types of stainless steel (SS) can be found in the literature (see for example Refs. [10, 18, 20, 21]) showing a wide range of values. One sample of type 304L (a vacuum system piece from Pfeiffer ${ }^{14}$ ) was screened using the Paquito detector (see results in row \#14 of table 3), obtaining the usual quite high levels of activity from natural chains. Material referenced as austenitic 1.4571 (also 316L) has been extensively studied by XENON [17] and GERDA [31] experiments, finding materials supplied by the Nironit company ${ }^{15}$ with activity levels (values or upper limits) of even tenths of $\mathrm{mBq} / \mathrm{kg}$ for isotopes from the natural chains in the best cases. Three samples of 316Ti stainless steel supplied by Nironit were screened at LSC and results are presented at rows \#15-17 of table 3; they have different thickness since they are intended to be used in different parts of the NEXT pressure vessel $(10 \mathrm{~mm}$ for body, $15 \mathrm{~mm}$ for end-caps and $50 \mathrm{~mm}$ for flanges). Activities from ${ }^{60} \mathrm{Co}$ and ${ }^{54} \mathrm{Mn}$, commonly present in steel, have been quantified for the three samples. Results for cosmogenic ${ }^{54} \mathrm{Mn}$, not quoted in table 3 , are $0.29 \pm 0.05,0.55 \pm 0.07$ and $0.97 \pm 0.14 \mathrm{mBq} / \mathrm{kg}$ for increasing thickness of sample. For the 10and 15-mm-thick samples, upper bounds for all the other emitters investigated have been derived;

\footnotetext{
${ }^{12} \mathrm{http}: / /$ www.titaniosmp.com

${ }^{13} \mathrm{http} / / / \mathrm{www} \cdot \mathrm{titaniummetalsupply.com}$

${ }^{14}$ http://www.pfeiffer-vacuum.com

${ }^{15} \mathrm{http} / / / \mathrm{www} \cdot$ nironit.de
} 
for the 50-mm-thick sample, the activity of the isotopes of the ${ }^{232} \mathrm{Th}$ chain has been quantified, pointing to secular equilibrium. It is worth noting that the sensitivity for the thickest sample was worse than for the other two, because of the lower mass available in the sample (see table 2) and the lower efficiency detection due to self-absorption. The activity values obtained for Nironit 316Ti stainless steel are of the order or below NEXT requirements; therefore, the booked batches from where the samples were taken will be used for pressure vessel construction.

Samples of inconel 718 and inconel 625 from the Spanish company Mecanizados Kanter ${ }^{16}$ were screened at LSC and results are shown in rows \#18-19 of table 3. No previous results on radiopurity of this material have been found; upper limits on activities of the lower parts of the ${ }^{238} \mathrm{U}$ and ${ }^{232} \mathrm{Th}$ chains have been set at some $\mathrm{mBq} / \mathrm{kg}$ for both types of inconel. Presence of ${ }^{58} \mathrm{Co}$ was identified for inconel 625 .

\subsection{High Voltage and Electroluminescence components}

The main body of the field cage to be placed inside the vessel will be made of high density polyethylene, with attached copper strips connected to resistors [3] ; PEEK was also considered as an alternative. Wire meshes separating the different field regions of the detector, including the electroluminescence volume, will be made of stainless steel. To improve the light collection efficiency of the detector, reflector panels coated with a wavelength shifter will cover the inner part of the field cage. This light tube will be made of Tetratex $($ fixed over a $3 \mathrm{M}$ substrate, coated with tetraphenyl butadiene (TPB) [3]. The ArDM experiment has screened specifically polytetrafluoroethylene (PTFE) Tetratex from Donaldson Membranes ${ }^{17}$ by Inductively Coupled Plasma Mass Spectrometry (ICPMS) [32] and TPB from two different manufacturers were measured at SNOlab [18].

A sample of PEEK from Sanmetal Spanish company was screened using the Paquito detector; values obtained are shown in row \#20 of table B, pointing to a non-negligible activity. Only upper bounds on activity of PEEK were presented in [19].

Polyethylene from IN2 Plastics company ${ }^{18}$ has a very good radiopurity according to XENON results [17] and a sample of High Molecular Weight polyethylene (type PE500) was therefore chosen for screening at LSC. First results, shown in row \#21 of table 3, have produced only upper limits for common radioisotopes. Semitronß ES225 plastic produced by Quadrant Engineering Plastic Products ${ }^{19}$ has been also measured and the results on its radiopurity are presented in row \#22 of table 3; in this case, a quite high activity of ${ }^{40} \mathrm{~K}$ has been registered.

Surface Mount Device (SMD) resistors supplied by Farnell ${ }^{20}$ and by Finechem ${ }^{21}$ were screened at LSC (see results in rows \#23-24 of table 3). Activity values obtained for Finechem resistors are much lower than for Farnell ones, and very similar to those obtained in 17] for resistors of the same type and company.

\footnotetext{
${ }^{16} \mathrm{http}: / /$ www.mecanizados-kanter.es

${ }^{17} \mathrm{http} / / /$ www.donaldson.com

${ }^{18} \mathrm{http} / / / \mathrm{www}$. in2plastics.com

${ }^{19} \mathrm{http}: / / \mathrm{www} . q u a d r a n t p l a s t i c s . c o m$

${ }^{20} \mathrm{http}$ ://www.farnell.com

${ }^{21}$ http://www.jfine.co.jp
} 


\subsection{Energy and tracking planes components}

The energy measurement in NEXT is provided by the detection of the electroluminescence light by an array of photomultipliers (the so-called energy plane), located behind the cathode mesh. Those photomultipliers will also record the primary scintillation light that indicates the start of the event. Each photomultiplier will be sealed into individual, pressure resistant, vacuum tight copper enclosures and will be coupled to the sensitive volume through a sapphire window coated with TPB. The tracking function will be provided by a plane of MPPCs operating as sensor pixels and located behind the transparent electroluminescence gap. The MPPCs will be mounted on square boards named Dice Boards (DB); each DB will contain $8 \times 8$ sensors with a pitch of $\sim 1 \mathrm{~cm}$ and will be coated with TPB too. The array of DBs, with $\sim 7000$ channels, forms the tracking plane. Front-end electronics boards for this tracking plane will be inside the pressure vessel, behind a copper shield. Details can be found in [3].

Although different models of photomultipliers were under consideration, Hamamatsu R11410MOD was finally chosen for the NEXT-100 detector since radiopurity specifications provided by Hamamatsu are better than for other models $\left(\sim 3.3 \mathrm{mBq} / \mathrm{PMT}\right.$ of ${ }^{238} \mathrm{U}, \sim 2.3 \mathrm{mBq} / \mathrm{PMT}$ of ${ }^{232} \mathrm{Th}$ and $\sim 5.7 \mathrm{mBq} / \mathrm{PMT}$ of ${ }^{40} \mathrm{~K}$ ). The XENON [17] and LUX [33] experiments have studied the radiopurity of this model, finding even lower activities. These levels would satisfy NEXT requirements, but the dispersion found in different measurements imposes a dedicated program to control the photomultiplier radiopurity, which will be undertaken in LSC. Sapphire windows (from Swiss Jewel Company ${ }^{22}$ ) were screened by EXO [12] with activities of tenths of $\mathrm{mBq} / \mathrm{kg}$ from the natural chains; a measurement of sapphire windows for NEXT is underway.

Silicon, used for the MPPCs at the tracking plane, is, as germanium, a very radiopure material with typical intrinsic activities of ${ }^{238} \mathrm{U}$ and ${ }^{232} \mathrm{Th}$ at the level of few $\mu \mathrm{Bq} / \mathrm{kg}$ [6]. In any case, a specific measurement of MPPCs is pending, either separately or after being mounted on the boards.

Several materials have been taken into consideration for Printed Circuit Boards (PCBs) and a large number of radiopurity measurements can be found in [21]. FR4 was disregarded for both an unacceptable high rate of outgassing and bad radiopurity (a fast measurement made with Paquito detector pointed to activities of hundreds of $\mathrm{mBq} / \mathrm{kg}$ for natural chains); it seems that the glass fiberreinforced materials at base plates of circuit boards can be a source of radioactive contamination [6]. Components made of just kapton (like cirlex) and copper offer very good radiopurity, as shown in the measurements of kapton-copper foils in [24] and in the screening of a monolayer PCB made of kapton and copper supplied by LabCircuits ${ }^{23}$ using the Paquito detector, presented in row \#25 of table 3. Also cuflon $\AA$ offers low activity levels, as shown in the measurement of samples from Crane Polyflon ${ }^{24}$ by GERDA [14] and at [15], using both ICPMS and Ge gamma spectroscopy. A first measurement of Polyflon cuflon made of a 3.18-mm-thick PTFE layer sandwiched by two 35$\mu \mathrm{m}$-thick copper sheets was made for NEXT and results are shown in row \#26 of table B. Cuflon has been chosen for the Dice Boards. Adhesive films to glue cuflon sheets are used to prepare multilayer PCBs; a sample of bonding films made of a polyolefin co-polymer and supplied also by Crane Polyflon were screened and results are presented in row \#27 of table 3 . Despite the high

\footnotetext{
${ }^{22} \mathrm{http}: / / \mathrm{www}$. swissjewel.com

${ }^{23} \mathrm{http}: / / \mathrm{www} .1 \mathrm{ab}-$ circuits.com

${ }^{24}$ http://www.polyflon.com
} 
activities measured, the use of these films is not completely discarded since the necessary mass for each Dice Board is of only $0.59 \mathrm{~g}$.

Information is also available on the radiopurity of different types of connectors [10, 18, 21]. FFC/FCP (Flexible Printed Circuit \& Flexible Flat Cable) connectors were initially considered for the DBs; connectors supplied by Hirose ${ }^{25}$ were selected and screened using the Paquito detector, as well as similar connectors from Panasonic ${ }^{26}$ (see results in rows \#28-29 of table B). Both types of connectors show activities of at least several $\mathrm{mBq} / \mathrm{pc}$ for isotopes in ${ }^{232} \mathrm{Th}$ and the lower part of ${ }^{238} \mathrm{U}$ chains and for ${ }^{40} \mathrm{~K}$. These values, according to [21], are of the same order than those for similar connectors supplied by Molex ${ }^{27}$; all of them are made of Liquid Crystal Polymer (LCP), thus it seems that the activity measured is related to this material. Thermoplastic connectors 503066-8011 from Molex were also screened (see results in row \#30 of table 3) finding activities slightly smaller but of the same order. Since these levels are too high for NEXT sensitivity, it was concluded that this kind of connectors must be avoided at DBs and the collaboration is at the moment foreseeing a direct bonding of the FFCs/FCPs to the DBs. A sample of lead free $\mathrm{SnAgCu}$ solder paste supplied by Multicore (Ref. 698840) has been screened and results are presented in row \#31 of table B). ${ }^{108 m} \mathrm{Ag}$, induced by neutron interactions and having a half-life of $\mathrm{T}_{1 / 2}=438 \mathrm{y}$, has been identified in the paste, with an activity of $5.26 \pm 0.40 \mathrm{mBq} / \mathrm{kg}$, while upper limits of a few $\mathrm{mBq} / \mathrm{kg}$ have been set for the common radioactive isotopes; consequently, this solder paste could be used without concern. Solder wire with similar composition from Multicore (Ref. 442578) was also screened (see row \#32 of table 3 ), finding in this case a high activity of the lower part of the ${ }^{238} \mathrm{U}$ chain. An activity of ${ }^{210} \mathrm{~Pb}$ of $(1.2 \pm 0.4) \times 10^{3} \mathrm{~Bq} / \mathrm{kg}$ has been deduced using the bremsstrahlung emission from its daughter nuclide ${ }^{210} \mathrm{Bi}[34]$.

Concerning electronic components at the boards, ceramic capacitors seem to be quite radioactive [21] and have been disregarded. Tantalum capacitors (Vishay Sprague 597D ${ }^{28}$ ) have been screened at LSC and results are presented in row \#33 of table 3; activity levels are lower than for tantalum capacitors supplied by $\mathrm{AVX}^{29}$, from database in [21]. In addition to activities shown in table 3, the presence of ${ }^{182} \mathrm{Ta}$ (beta emitter with $\mathrm{Q}=1814.3 \mathrm{keV}$ and $\mathrm{T}_{1 / 2}=(114.74 \pm 0.12$ ) days [35], produced by neutron activation on ${ }^{181} \mathrm{Ta}$ ) has been identified through the observation of many of its gamma emissions.

\section{Summary}

A thorough radiopurity control is being performed for the construction of the NEXT-100 double beta decay experiment to be operated at LSC. Evaluation of activity levels in the most relevant materials has been carried out based on GDMS and on ultra-low background germanium gamma-ray spectrometry at LSC. Some of the results presented here represents the first measurements performed using the germanium detectors of the LSC Radiopurity Service. This kind of data have a widespread interest, being also useful for other experiments investigating rare phenomena in under-

\footnotetext{
25 http://www.hirose.com

${ }^{26} \mathrm{http}: / / \mathrm{www} \cdot$ panasonic-electric-works.com

${ }^{27}$ http://www.molex.com

${ }^{28}$ http://www.vishay.com

${ }^{29}$ http://www.avx.com
} 
ground laboratories. Radiopurity information is expected to be helpful not only for the selection of materials that are radiopure enough to minimize the background level, but also for the development of the NEXT detector background model in combination with Monte Carlo simulations.

Adequate materials for the external and internal passive shields have been identified. Titanium and stainless steel samples were analyzed for the construction of the pressure vessel. The good radiopurity found for the 316Ti stainless steel supplied by the Nironit company, of the order of tenths of $\mathrm{mBq} / \mathrm{kg}$ for the isotopes at the lower part of the ${ }^{238} \mathrm{U}$ and ${ }^{232} \mathrm{Th}$ chains, confirmed that this material can be used for the detector vessel in combination with an inner copper shield. The background contribution of the vessel and both internal and external shields has been studied, assuming the upper limits on the activities obtained here for Nironit 316Ti stainless steel, Luvata copper and Tecnibusa lead; the preliminary results indicate, for each material, a background level in the RoI at most of the order of $10^{-4}$ counts $\mathrm{keV}^{-1} \mathrm{~kg}^{-1} \mathrm{y}^{-1}$, after all cuts (fiducial and topological). Construction of shielding and vessel is thus proceeding.

Selection of in-vessel components to be used at the energy and tracking planes has been performed too, helping in the design of DB and front-end electronics boards. While resistors, capacitors and solder paste of acceptable radiopurity have been found, board-to-cable connectors containing LCP have been discarded since they have activities of few $\mathrm{mBq}$ per piece for isotopes of the ${ }^{238} \mathrm{U}$ and ${ }^{232} \mathrm{Th}$ chains. Cuflon, being radiopure enough, has been chosen for the construction of the boards for the MPPCs.

Further radiopurity measurements using germanium detectors at LSC are scheduled before the installation and operation of the NEXT detector with the aim to control all the components that might contribute significantly to the background. Main efforts will be devoted to the careful selection of photomultipliers of the chosen model (Hamamatsu R11410MOD) and to the screening of related components (e.g., saphire windows, bases and cans) at the energy plane and light tube materials. This task is essential to achieve the required background level in the region of interest imposed by the NEXT sensitivity goal.

\section{Acknowledgments}

We deeply acknowledge LSC directorate and staff for their strong support for performing the measurements at the LSC Radiopurity Service. The NEXT Collaboration acknowledges funding support from the following agencies and institutions: the Spanish Ministerio de Economía y Competitividad under grants CONSOLIDER-Ingenio 2010 CSD2008-0037 (CUP), Consolider-Ingenio 2010 CSD2007- 00042 (CPAN), and under contracts ref. FPA2008-03456, FPA2009-13697-C0404; FCT(Lisbon) and FEDER under grant PTDC/FIS/103860/2008; the European Commission under the European Research Council T-REX Starting Grant ref. ERC-2009-StG-240054 of the IDEAS program of the 7th EU Framework Program; Director, Office of Science, Office of Basic Energy Sciences, of the US Department of Energy under contract no. DE-AC02-05CH11231. Part of these grants are funded by the European Regional Development Fund (ERDF/FEDER). J. Renner (LBNL) acknowledges the support of a US DOE NNSA Stewardship Science Graduate

Fellowship under contract no. DE-FC52-08NA28752. F. I. acknowledges the support from the Eurotalents program. 


\section{References}

[1] J.J. Gomez-Cadenas et al, The search for neutrinoless double beta decay, Riv. Nuovo Cim. 35 (2012) 29-98.

S. R. Elliott, Recent Progress in Double Beta Decay, Mod. Phys. Lett. A 27 (2012) 1230009.

F. T. Avignone III et al., Double Beta Decay, Majorana Neutrinos, and Neutrino Mass, Rev. Mod. Phys. 80 (2008) 481.

[2] http://www.lsc-canfranc.es

[3] V. Alvarez et al., NEXT-100 Technical Design Report (TDR). Executive summary, JINST 7 (2012) T06001.

[4] J.J. Gomez-Cadenas et al., Sense and sensitivity of double beta decay experiments, J. Cosmol. Astropart. Phys. 06 (2011) 007.

[5] N. Yahlali, I. G. Irastorza for the NEXT Collaboration, First NEXT prototypes for double-beta decay search, Nucl. Instrum. Meth. A 628 (2011) 162-165.

[6] G. Heusser, Low-radioactivity background techniques, Annu. Rev. Nucl. Part. Sci. 45 (1995) 543-590.

[7] J. A. Formaggio and C. J. Martoff, Backgrounds to sensitive experiments underground, Annu. Rev. Nucl. Part. Sci. 54 (2004) 361-412

[8] S. Cebrián et al., Performances and prospects of the ROSEBUD dark matter search experiment, Astropart. Phys. 10 (1999) 361-368.

[9] H. Nedera, G. Heussera, and M. Laubenstein, Low level gamma-ray germanium-spectrometer to measure very low primordial radionuclide concentrations, Appl. Rad. and Isot. 53 (2000) 191-195.

[10] C. Arpesella et al., Measurements of extremely low radioactivity levels in BOREXINO, Astropart. Phys. 18 (2002) 1-25.

[11] M. Laubenstein et al., Underground measurements of radioactivity, Appl. Rad. and Isot. 61 (2004) 167-172.

[12] S. Leonard et al., Systematic study of trace radioactive impurities in candidate construction materials for EXO-200, Nucl. Instrum. Meth. A 591 (2008) 490.

[13] D. Budjas et al., Highly sensitive gamma-spectrometers of GERDA for material screening: Part I, Proceedings of the XIV International Baksan School Particles and Cosmology Baksan Valley, Kabardino-Balkaria, Russia, April 16-21, 2007, INR RAS, Moscow 2008 pp. 228-232 [arxiv:0812.0723].

[14] D. Budjas et al., Gamma-ray spectrometry of ultra low levels of radioactivity within the material screening program for the GERDA experiment, Appl. Rad. and Isot. 67 (2009) 755.

[15] S. Nisi et al., Comparison of inductively coupled mass spectrimetry and ultra low-level gamma-ray spectroscopy for ultra low background material selection, Appl. Rad. and Isot. 67 (2009) 828.

[16] L. Baudis et al., Gator: a low-background counting facility at the Gran Sasso Underground Laboratory, JINST 6 (2011) P08010.

[17] E. Aprile et al., Material screening and selection for XENON100, Astropart. Phys. 35 (2011) 43-49.

[18] I. Lawson and B. Cleveland, Low Background Counting At SNOLAB, AIP Conf. Proc. 1338 (2011) 68-77. 
[19] P. Finnerty et al., Low-background gamma counting at the Kimballton Underground Research Facility, Nucl. Instrum. Meth. A 642 (2011) 65-69.

[20] UKDMC Radioactivity Data, http://hepwww.rl.ac.uk/UKDMC/Radioactivity/.

[21] ILIAS Database, http://radiopurity.in2p3.fr.

[22] M. Redshaw et al., Mass and Double-Beta-Decay Q Value of ${ }^{136}$ Xe, Phys. Rev. Lett. 98 (2007) 053003.

[23] A. Bettini, Underground laboratories, Nucl. Instrum. Meth. A 626-627 (2011) S64-S68.

[24] S. Cebrián et al., Radiopurity of micromegas readout planes, Astropart. Phys. 34 (2011) 354-359.

[25] Ll. A. Currie, Limits for qualitative detection and quantitative determination. Application to radiochemistry, Anal. Chem. 40 (1968) 586-377.

[26] Ch. Hurtgen et al., Revisiting Currie: how long can you go?, Appl. Rad. Isot. 53 (2000) 45-50.

[27] S. Agostinelli et al., GEANT4-a simulation toolkit, Nucl. Instrum. Meth. A 506 (2003) 250.

[28] GEANT4 Collaboration, Physics Reference Manual, http://geant4.cern.ch/support/userdocuments.shtml.

[29] A. Alessandrello et al., Measurements on radioactivity of ancient roman lead to be used as shield in searches for rare events, Nucl. Instrum. Meth. B 61 (1991) 106-117.

[30] D. S. Akerib et al., Radio-assay of Titanium samples for the LUX Experiment, arXiv:1112.1376 [physics.ins-det].

[31] W. Maneschg et al., Measurements of extremely low radioactivity levels in stainless steel for GERDA, Nucl. Instrum. Meth. A 593 (2008) 448.

[32] V. Boccone et al., Development of wavelength shifter coated reflectors for the ArDM argon dark matter detector, JINST 4 (2009) P06001.

[33] D. S. Akerib et al., An Ultra-Low Background PMT for Liquid Xenon Detectors, arXiv:1205.2272 [physics.ins-det].

[34] A. Nachab and Ph. Hubert, ${ }^{210} \mathrm{~Pb}$ activity by detection of bremsstrahlung in ${ }^{210}$ Bi beta-decay, Nucl. Instrum. Meth. B 274 (2012) 188-190.

[35] B. Singh and J. C. Roediger, Nuclear Data Sheets for A=182, Nuclear Data Sheets 111 (2010) 2081-2330. 